TRABAJOS DE PREHISTORIA

52, n. ${ }^{\circ}$, 1995 , pp. 145-155

\section{INDICADORES QUÍMICOS DE COMBUSTIÓN EN UN HOGAR DEL PALEOLÍTICO MEDIO DEL YACIMIENTO DE MEDIONA I (ALT PENEDÈS, BARCELONA)}

\author{
CHEMICAL MARKERS OF COMBUS- \\ TION IN A HEARTH FROM THE \\ MIDDLE PALEOLITHIC MEDIONA I \\ SITE (ALT PENEDĖS, BARCELONA)
}

\author{
JOAN MIQUEL LOZANO (*) \\ RAFEL SIMÓ (**) \\ IOAN O. GRIMALT $(* *)$ \\ JORDI ESTEVEZ (*)
}

\section{RESUMEN}

La aplicación del análisis químico orgánico a muestras arqueológicas es una técnica de desarrollo reciente. El estudio de la fracción lipídica (eso es, la fracción de materia extraíble mediante disolventes orgánicos) de restos sedimentarios en yacimientos permite recuperar una información inaccesible a otras técnicas de identificación aplicadas a la Arqueología. Este artículo describe de forma comparativa la fracción aromática del sedimento en el interior y en el exterior de un área de combustión en un yacimiento paleolítico previamente excavado.

Asimismo, presenta el análisis de indicadores químicos pirogénicos con una técnica de gran potencial para la identificación de áreas de combustión en yacimientos donde éstos no están claramente definidos (simples manchas sin carbones, agrupación de piedras sin evidencias externas de termoalteración, etc.), siempre comparándo-

(*) Departament d'Història de les Societats Pre-capitalistes. Facultat de Lletres. Universitat Autònoma de Barcelona. 08193 Bellaterra, Barcelona.

(**) Departament de Química Ambiental. CID-CSIC. c/ Jordi Girona, 18-26. 08034 Barcelona.

Este artículo fue remitido en su versión final el 14-VI-95. las con muestras de sedimento no termoalterado del mismo nivel arqueológico.
ABSTRACT
Organical chemical analysis of archaeological soils is a recently developed technique, which considerably in- creases the information available from ancient remains. The present study gives an example of their capabilities in the reconstruction of the paleoenvironment in the Middle Paleolithic Mediona I site.
Pyrogenic chemical-markers have been identified from the study of the lipid aromatic fraction in a pre- viously excavated combustion area.
These compounds have made it possible to recognize hearths which are not clearly defined by other means.
Palabras-clave: Paleolítico Medio. Área de combustión. Fracción lipídica. Cromatografía de gases. Espectrome- tría de Masas. (HAP) Hidrocarburos Aromáticos Policí- clicos. Reteno.
Key words: Middle Paleolithic. Combustion Area. Lipid Fraction. Gas Cromatography. Mass Spectrometry. (PAH) Policyclic Aromatic Hidrocarbons. Retene. 


\section{INTRODUCCION}

Los análisis químicos aplicados a la arqueología se han utilizado desde antiguo. Los primeros análisis químicos estudiaban sólo la materia inorgánica. El objeto de estudio eran los elementos arqueológicos en sí, cerámica, útiles de piedra, utensilios metálicos, etc., con el fin de conocer tanto su origen como su composición.

Es posteriormente cuando se empiezan a realizar análisis químicos de la materia orgánica, tanto de los objetos (madera, hueso, etc.) como de los sedimentos arqueológicos. El estudio de los ácidos grasos de sedimentos arqueológicos se inicia con los trabajos de Rottländer (1976, 1986, 1990) quien identificó los restos de un caballo en el yacimiento de la Caune de l'Arago en Tautavel de una antigüedad entre 230000-500000 años — demostrando la perduración de la materia orgánica en sedimentos arqueológicos - , así como los restos de un elefante en el yacimiento pleistocénico de Stuttgart-Bad Cannstatter. La técnica que utilizaba se basaba en el estudio de los ácidos grasos de sedimentos mediante cromatografía de gases.

Un salto cualitativo lo tenemos con los trabajos de March $(1989,1991)$ sobre ácidos grasos contenidos en sedimentos de estructuras de combustión arqueológicas de los yacimientos argentinos de Túnel I, Tomayoc I, etc. La técnica empleada es cada vez más sofisticada: cromatografía de gases acoplada a un espectómetro de masas. El objetivo de sus trabajos es conocer el combustible empleado en los fogones y la duración de los mismos.

Los datos que obtenemos mediante el análisis químico de la fracción lipídica de los sedimentos arqueológicos aumentan y completan la información obtenida mediante otros tipos de análisis como la micromorfología de suelos, antracología, etc. El análisis de la fracción lipídica aromática nos revela si el sedimento arqueológico ha sufrido alguna termoalteración, sobre todo en yacimientos donde no aparezca claramente la asociación de elementos que conforman un área de combustión (cenizas, carbones, etc.).

\section{EL YACIMIENTO DE MEDIONA I: MARCO GEOGRÁFICO Y GEOLÓGICO}

Las muestras analizadas en este trabajo proceden de un área de combustión, previamente excavada, del yacimiento Mediona I (Mediona, Barcelona), dentro del marco del proyecto «El poblamiento prehistórico en la cuenca del Mediona» (Estévez et alii, 1990, 1991, 1993). El área de combustión ha sido estudiado mediante análisis de micromorfología de suelos (Taulé, 1994), y análisis antracológico (Piqué, 1992), de esta manera podremos comprobar la potencialidad de la técnica para su posterior aplicación a otros yacimientos sin posibilidad de este tipo de análisis.

El yacimiento de Mediona I se encuentra en la zona de contacto entre el Macizo de Gaià y la Depresión del Penedès, en el valle del río Riudevitlles (Fig. 1). El Macizo de Gaià forma parte de la Cordillera Pre-litoral de Catalunya; por otro lado, la Depresión del Penedès forma parte de un gran paso natural de orientación NE-SO. Su situación sobre la falla que separa el Macizo de Gaià de la Fosa del Penedès provoca la surgencia de numerosas fuentes. Estas aguas presentan un alto contenido calcáreo que, al aflorar, ha ido produciendo formaciones travertínicas. Los travertinos han dejado registro de la existencia de una superposición de dos sistemas, con sendos pequeños lagos, en el Cuaternario reciente.

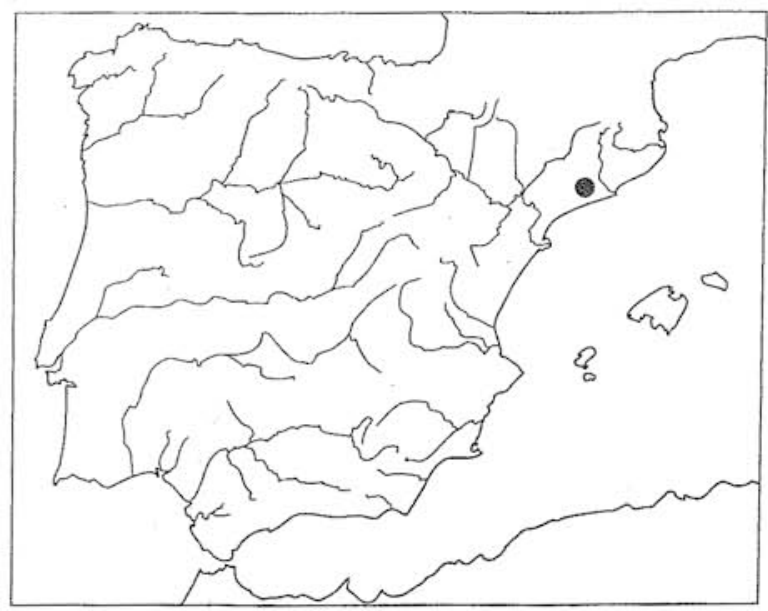

Fig. 1: Situación del yacimiento de Mediona I (Mediona, Barcelona) en la Península Ibérica.

El yacimiento se ubica en la zona norte de travertinos, en la ladera derecha del valle del río Mediona. Se extiende sobre una terraza de culti- 


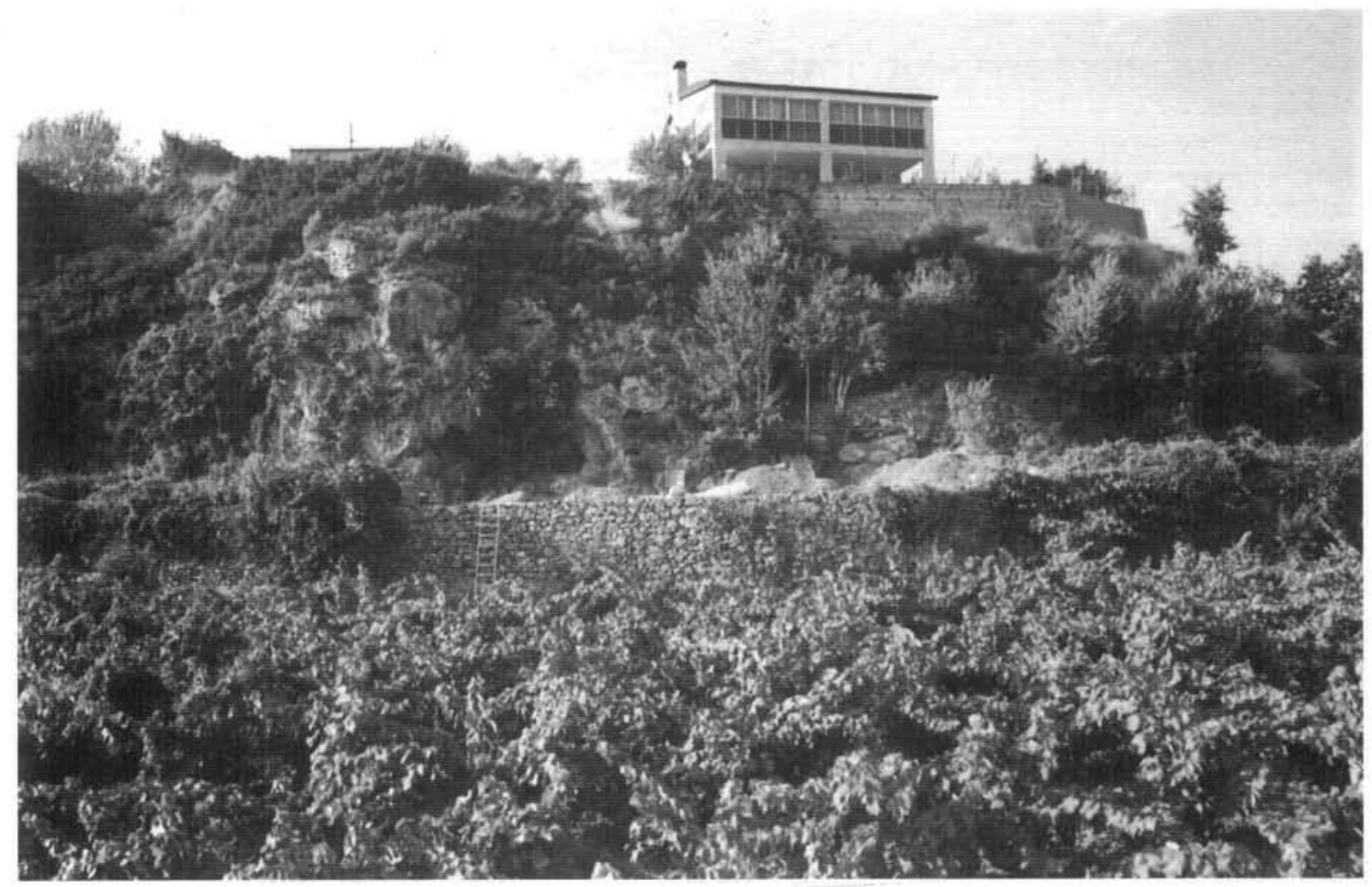

Lám. I: Vista general del yacimiento Mediona 1.

vo, frente a una pequeña cavidad, en las coordenadas $41^{\circ} 28^{\prime} 3$ '”, $1^{\circ} 28^{\prime} 25^{\prime \prime} \mathrm{W}$ y a $380 \mathrm{~m}$ sobre el nivel del mar (Lám. I). Ha proporcionado una serie de niveles arqueológicos que han sido excavados en sucesivas campañas entre los años 1987 y 1994 por arqueólogos de la Universitat Autònoma de Barcelona y del Instituto Arqueológico Alemán, y con la colaboración del CSIC.

Mediante el estudio de los registros lítico y faunístico, se ha situado el yacimiento en la tradición del Paleolítico Medio en Catalunya, lo cual se ha visto corroborado por algunas dataciones absolutas.

Durante la campaña de 1989 se excavó el área de combustión siguiendo la metodología desarrollada por G. Wúnsch (1991). Se hallaba ubicado en las cuadrículas J-33 y K-33. Previa delimitación, la excavación en corte sagital permitió descubrir que se trataba de un hogar en cubeta (Lám. II). En su parte superior aparecía una capa amarillenta de 1 ó $2 \mathrm{~cm}$ de ancho, aparentemente termoalterada. El cuerpo del hogar se situaba en el nivel arqueológico RO, y lo constituía un sedimento gris alterado, con piedras negruzcas y algunos carbones determinables. Su base ya pertenecía al siguiente nivel (ROI), era de textura más compacta y presentaba una tonalidad rojiza, con manchas amarillas (Fig. 2).

\section{MÉTODO EXPERIMENTAL}

\section{Toma de muestras}

La recogida de muestras para análisis químico debe realizarse con el mínimo contacto posible con materiales u objetos que puedan contener sustancias orgánicas. Los objetos metálicos utilizados han de lavarse previamente con disolventes orgánicos (acetona, diclorometano,...). Hay que evitar cualquier tipo de etiquetaje y sigla en contacto con el material a estudiar, 


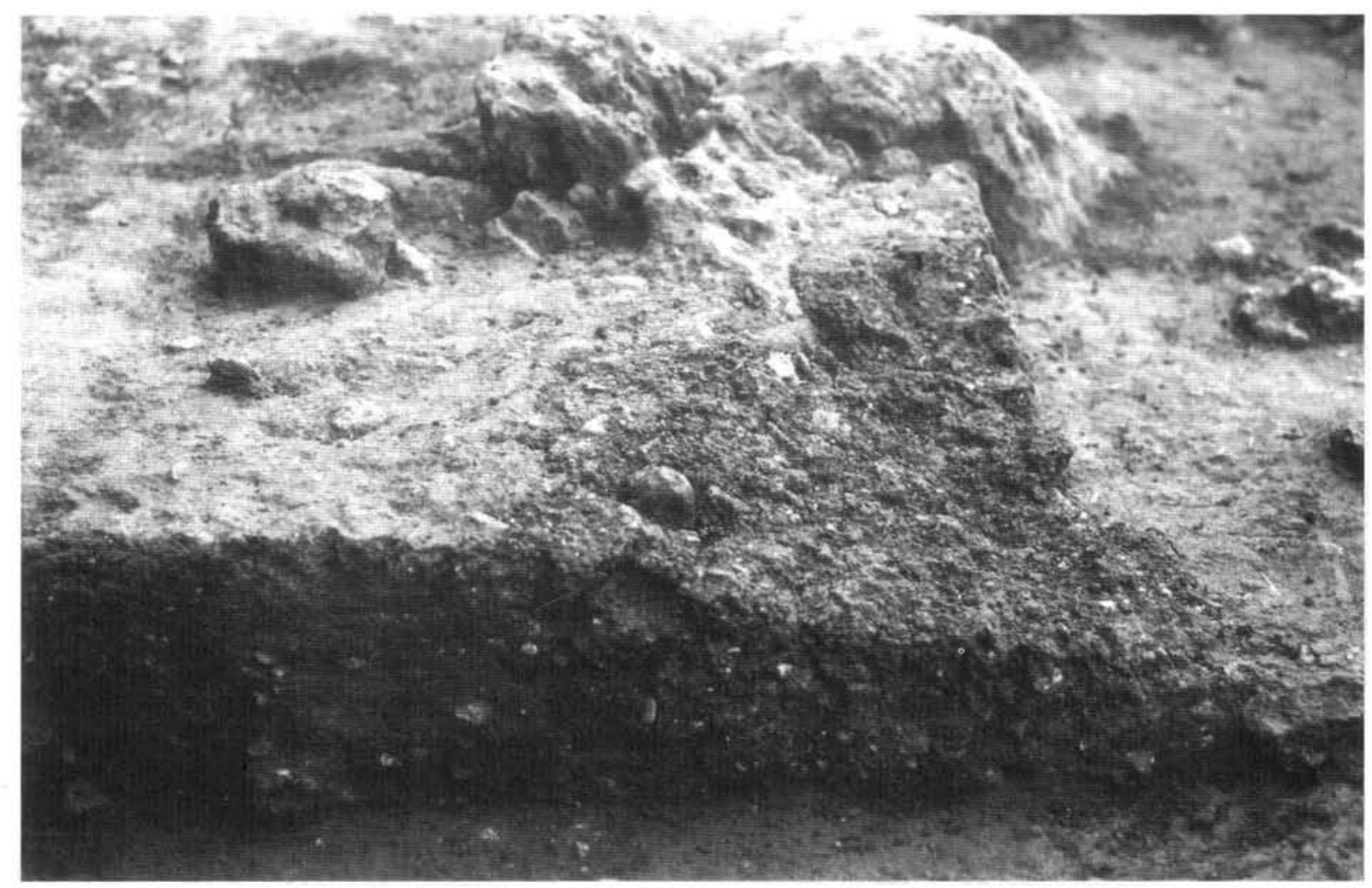

Lám. II: Sección del área de combustión en cubeta (Mediona I, Barcelona).

envolver el sedimento u objeto en papel de aluminio, y etiquetarlo exteriormente para que no pueda contaminarse la muestra.

La cantidad mínima de sedimento necesaria para el análisis debe ser entre 25-50 gr, aunque es recomendable recoger, siempre que sea posible, unos $100 \mathrm{gr}$ por si hay que realizar más de un análisis.

El tiempo aproximado del proceso de análisis de las muestras de sedimento (de 3 a 5 muestras) dura sobre 4 ó 5 días, dependiendo de la disponibilidad material del laboratorio. Económicamente, hay que tener en cuenta que si bien el material fungible empleado en los análisis no representa un alto coste, el instrumental analítico necesario sólo se encuentra en departamentos de investigación altamente especializados por su alto coste de inversión y mantenimiento. Debido a los pocos químicos con capacitación arqueológica y viceversa, nos encontramos ante la necesidad de formar una especialidad interdisciplinar que combine los conocimientos de las dos ciencias: química orgánica y arqueología.

El sedimento del área de combustión de Mediona I se recogió en su mayor parte, separando las muestras según la diferencia cromática del sedimento.

Se tomaron 5 muestras para el análisis de HAP (Hidrocarburos Aromáticos Policíclicos):

- FOG1S - capa termoalterada en la superficie. Color amarillento.

- FOG2E - sedimento de la mitad este del interior. Color gris.

- FOG3W - sedimento de la mitad oeste del interior. Color gris.

- FOG4B - sedimento de la base. Color rojizo con manchas amarillas.

- SET1 - sedimento del nivel geológico RO, no termoalterado (cuadrícula L-33). 
A
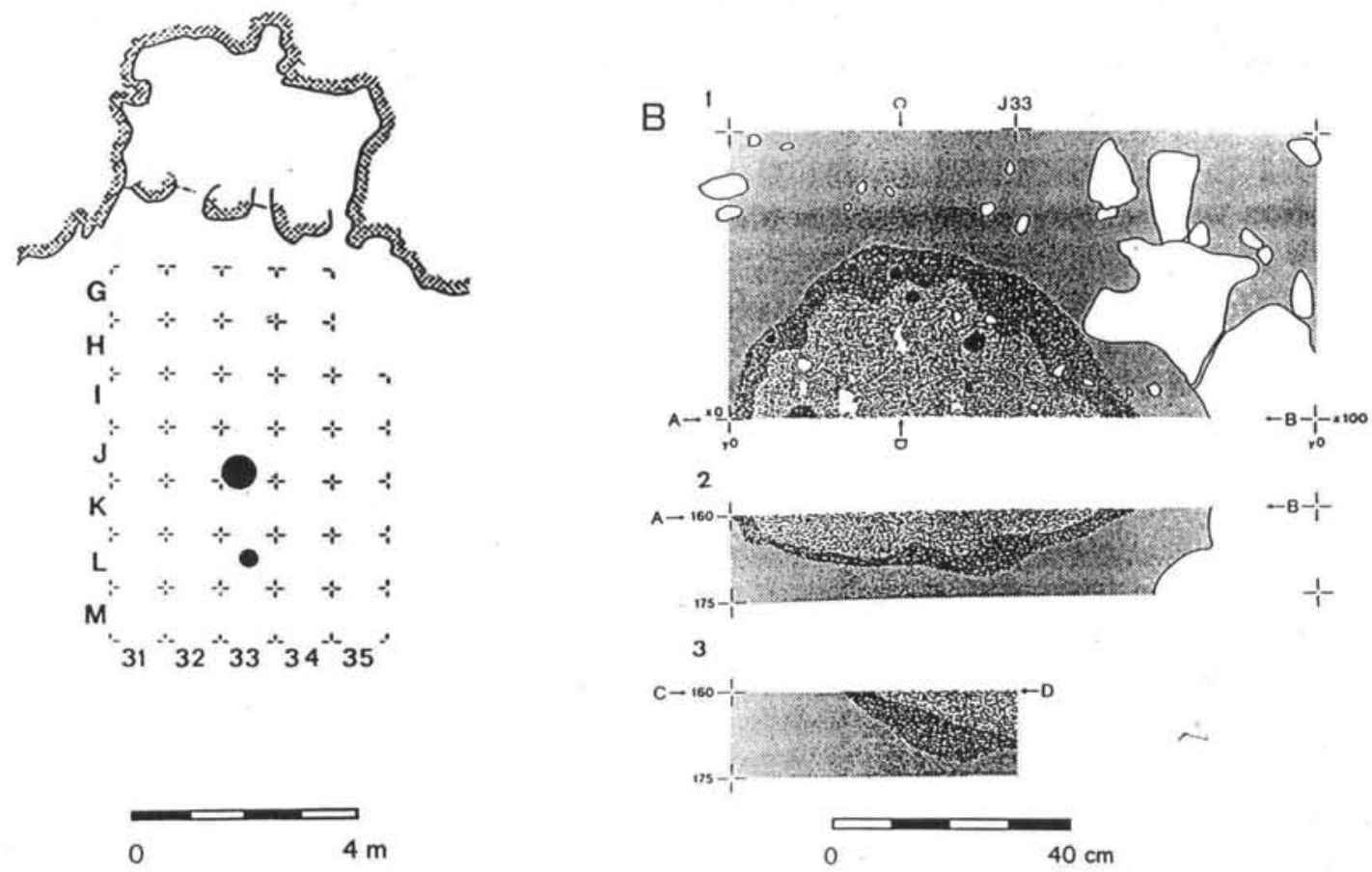

Fig. 2. A/. Situación del área de combustión en el yacimiento de Mediona I ( $\bullet$ área de combustión, • muestra sedimento exterior).

B/. Descripción gráfica del área de combustión: 1. Dibujo en planta. 2. Corte sagital. 3. Corte transversal.

\section{DESCRIPCIÓN DEL PROCEDIMIENTO ANALÍTICO}

\section{Extracción y fraccionamiento}

Muestras de 50 gr de sedimento se extrajeron en un aparato Soxhlet, durante $24 \mathrm{~h}$, con una mezcla de diclorometano y metanol 2:1 (v:v). La solución resultante se concentró por rotavaporación hasta un volumen de $2 \mathrm{ml}$, al que se añadieron $35 \mathrm{ml}$ de $\mathrm{KOH}$ al $6 \%$ en metanol. Después de unas $15 \mathrm{~h}$ de hidrólisis, se extrajo la fracción neutra con $\mathrm{n}$-hexano $(3 \times 30 \mathrm{ml})$, y de nuevo se concentró hasta un volumen de $0.5 \mathrm{ml}$. Los distintos grupos de lípidos neutros fueron separados mediante cromatografía de adsorción en una columna rellena con 8 gr de sílica (arriba) y 8 gr de alúmina (abajo), ambas desactivadas al $5 \%$ con agua. Siguiendo procedimientos previamen- te optimizados (Simó et alii., 1991a), se recogieron tres fracciones eluyendo con disolventes de polaridad creciente: F1, $20 \mathrm{ml}$ de hexano (hidrocarburos alifáticos); F2, $40 \mathrm{ml}$ de diclorometano al $50 \%$ en hexano (hidrocarburos aromáticos); F3, $40 \mathrm{ml}$ de metanol al $20 \%$ en diclorometano (lípidos polares). Cada una de las fracciones se concentró, primero al vacío y posteriormente con una corriente suave de nitrógeno, hasta llegar casi a sequedad.

\section{Análisis instrumental}

La determinación cualitativa y cuantitativa de la fracción aromática (F2) se llevó a cabo mediante cromatografía de gases con columna capilar (CG) acoplada a espectrometría de masas (EM), en un sistema Fisons MD800. La columna era una DB-5 (metilsiliconas) de $30 \mathrm{~m}$ x $0.25 \mathrm{~mm}$, con helio como gas portador y una 
programación de temperatura entre 60 y $300^{\circ} \mathrm{C}$. Temperaturas del EM: fuente de iones, $200^{\circ} \mathrm{C}$; línea de transferencia, $300^{\circ} \mathrm{C}$. Los datos de HAP se adquirieron mediante Impacto Electrónico $(70 \mathrm{eV})$ con Registro Selectivo de Iones, de acuerdo con un programa puesto a punto en trabajos anteriores (Simó et alii, 1991b)(Fig. 3).

\section{Los HAP como indicadores de combustión}

La combustión de materia orgánica debería resultar, en condiciones de máxima eficacia y oxigenación, en la formación de gases varios $\left(\mathrm{CO}_{2}, \mathrm{H}_{2} \mathrm{O}, \mathrm{SO}_{2}, \mathrm{NO}_{\mathrm{x}}\right)$ y de residuos sólidos básicamente inorgánicos. Sin embargo, una

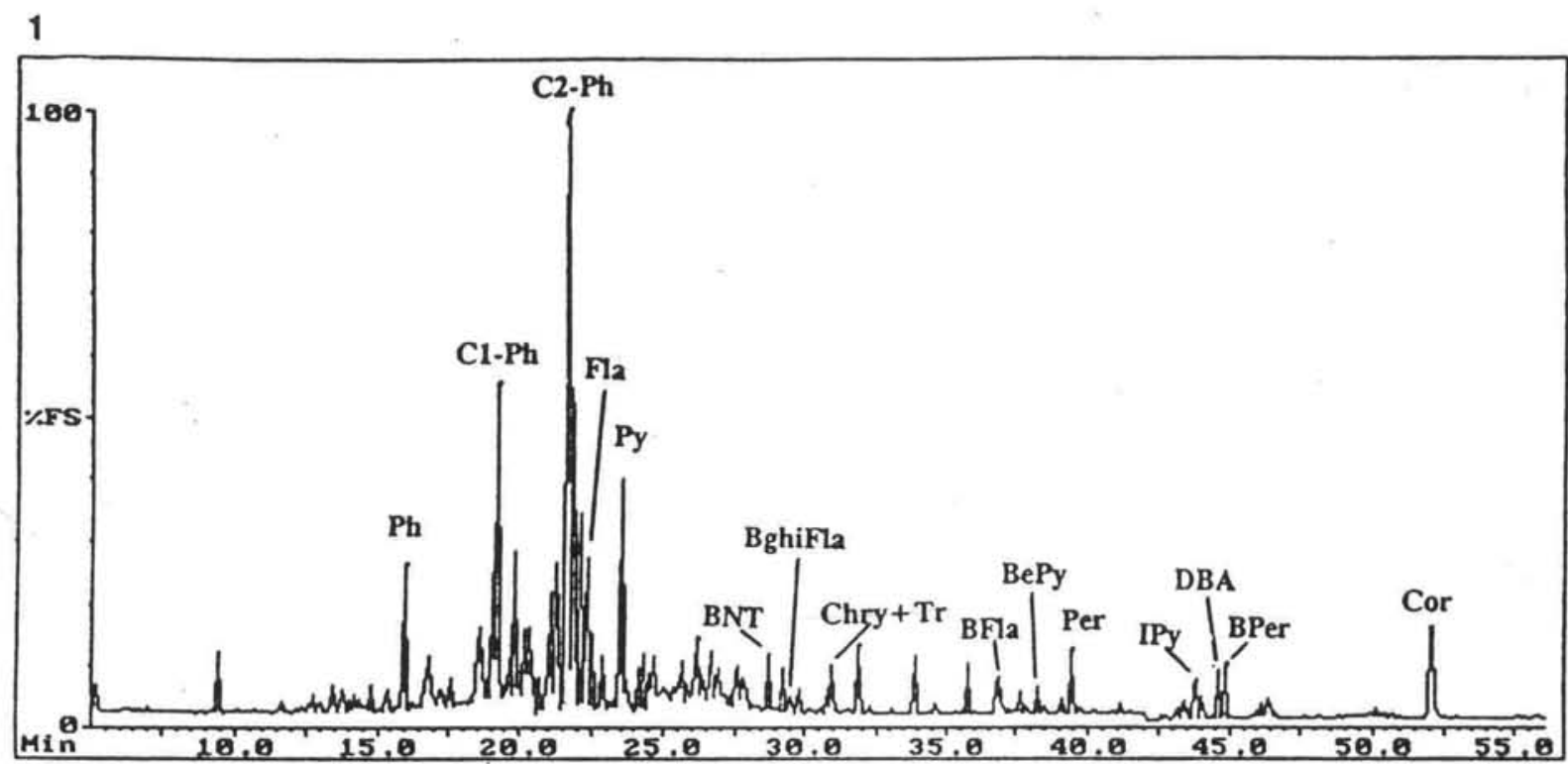

2

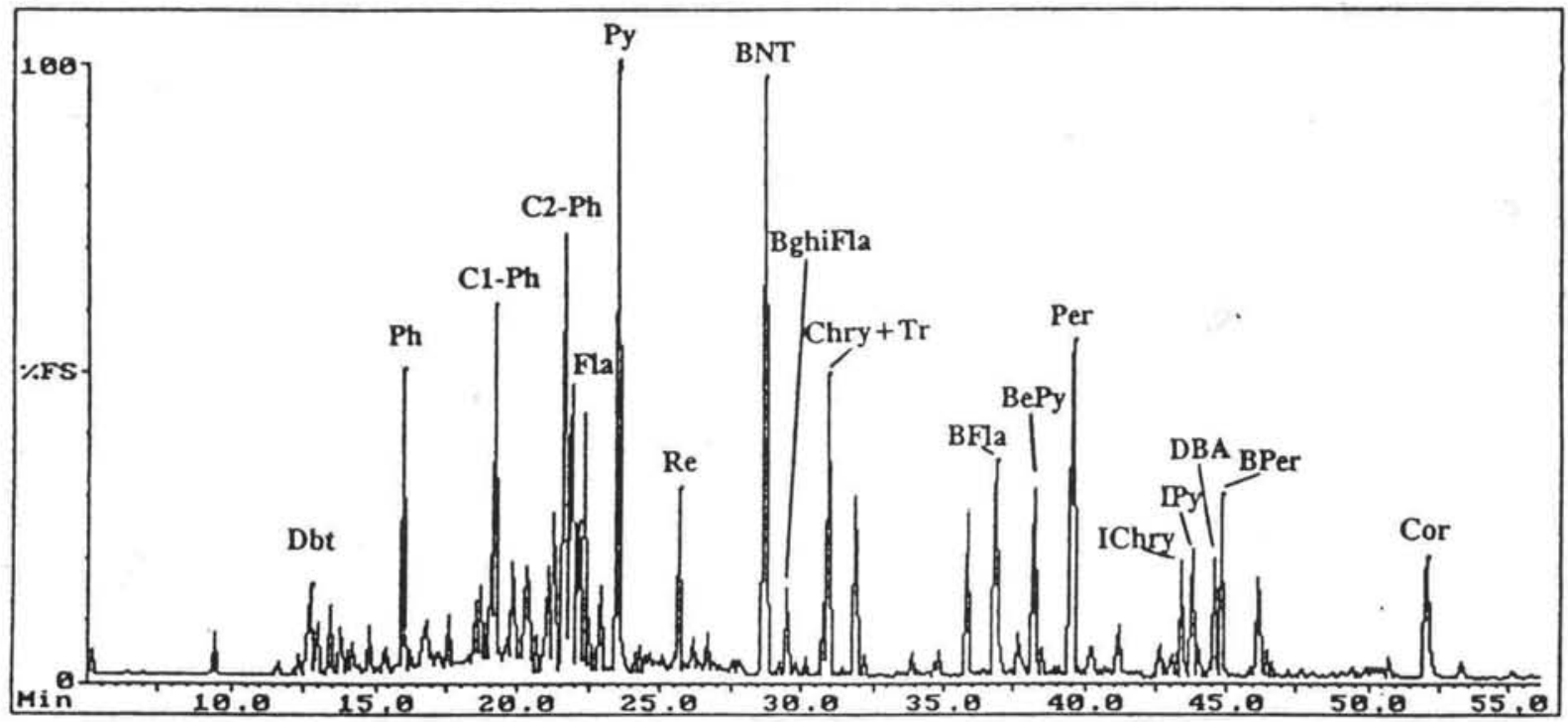

Fig. 3. C.I.T. Corriente Iónica Total de las fracciones aromáticas de las muestras: 1) SETI (muestra exterior), 2) FOG3W (sedimento interior) del área de combustión del yacimiento de Mediona I.

T. P., 52, n. ${ }^{\circ} 2,1995$ 
combustión como la que tiene lugar en un área de combustión doméstica o en un fuego al aire libre, lejos de las condiciones ideales, suele producir también un residuo sólido carbonáceo (hollín) y una gran variedad de moléculas orgánicas. El hollín es un material polimérico aromatizado que se forma a partir de radicales pequeños producidos durante la combustión (Miller y Fisk, 1987). Polimerizaciones incompletas en condiciones deficientes de oxígeno conducen a la formación, junto con el hollín, de hidrocarburos aromáticos policíclicos (HAP), los cuales constituyen una familia de contaminantes ampliamente difundidos en el medio ambiente. Además, independientemente de su concentración, los HAP constituyen excelentes indicadores de residuos de combustión en mues- tras ambientales, tanto recientes como antiguas. Ello es debido, por una parte, a que, a pesar de ser también constituyentes de combustibles fósiles crudos, ciertas distribuciones relativas de HAP tienen un origen unívocamente pirogénico. Por otra parte, son compuestos bastante persistentes en el medio, y esa resistencia a la degradación se ve aumentada al quedar adsorbidos sobre la superficie del hollín.

Un ejemplo reciente de la aplicación de los HAP como indicadores de combustión en paleoambientes lo constituye un estudio de la transición geológica Cretacio/Terciario en el que, por medio de la distribución de los HAP, se sugirió que un episodio generalizado de fuegos forestales arrasó la superficie terrestre tras el impacto de un meteorito (Venkatesan y Dahl, 1989).

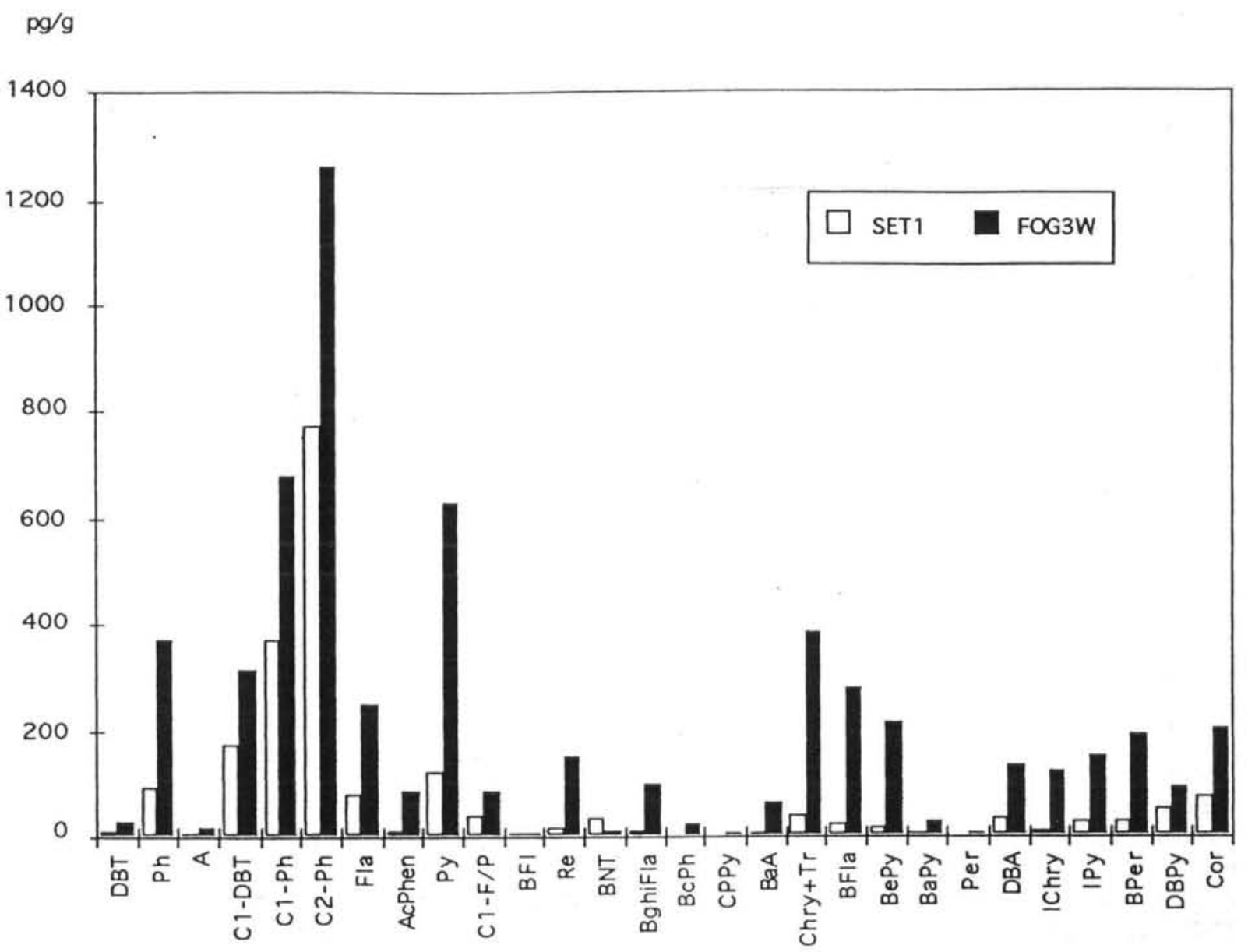

Fig. 4. Diagrama de barras comparativo de H.A.P. de las muestras SET1 y FOG3W (el significado completo de las abreviaturas con que se han designado los distintos H.A.P. se muestra al pie de la Tabla 1). 


\section{Distribuciones de HAP en las muestras de Mediona I}

La figura 4 muestra las distribuciones de los HAP determinados en los extractos de Mediona I (sus concentraciones se indican en la Tabla 1). En todas ellas los componentes mayoritarios son los de 3-4 anillos aromáticos (del dibenzotiofeno, DBT, al pireno, Py), siendo máximos los derivados metilados y en especial los dimetilfenantrenos $\left(\mathrm{C}_{2}-\mathrm{Ph}\right)$.

El predominio de los derivados metiiados de fenantreno y dibenzotiofeno sobre sus homólogos no metilados es una característica de los petróleos y bitúmenes, y se ha observado en suelos con nulo impacto antropogénico (Venkatesan y Dahl, 1989). Una combustión a temperatura moderada provoca un incremento de los derivados no metilados, llegando éstos a dominar netamente sobre los metilados en residuos de pirólisis a alta temperatura.

En este sentido, los porcentajes de derivados metilados sobre el total de HAP en el sedimento del yacimiento (Tabla 1) son claramente inferiores en el interior del área de combustión con respecto a las restantes muestras, lo que indica una probable presencia de residuos de combustión. En lo que se refiere, en concreto, a la serie del fenantreno, en la muestra exterior al área de combustión la relación fenantreno/(fenantreno + metil- + dimetilfenantrenos) es claramente favorable a los derivados metilados (0.07), y eso mismo se observa en la base del área de combustión (0.07). En cambio, en el interior y la superficie del área de combustión dicha relación aumenta significativamente $(0.15-0.25)$, lo que de nuevo es coherente con la presencia de residuos pirolizados.

Otra diferencia destacable entre el interior del área de combustión y las restantes muestras son las concentraciones relativas mucho mayores tanto de compuestos pericondensados (pireno, benzopirenos, benzo[g,h,i]perileno, coroneno) como de estructuras con un anillo alicíclico de 5 átomos de carbono (fluoranteno, benzofluorantenos). Su presencia da una nueva evidencia de la combustión de materia orgánica, puesto que dichos compuestos son poco frecuentes en petróleos y en cambio han sido hallados en pirolizados de madera, carbón, gasolina y gasoil (Li y Kamens, 1993).

Así, si consideramos como un solo grupo a los componentes pirogénicos de mayor peso molecular (eso es: benzo[a]antraceno, criseno+ trifenileno, benzofluoranteno, benzo[a]pireno, indeno[1,2,3-cd]pireno, benzo[g,h,i]perileno y coroneno), el porcentaje de dicho grupo con respecto al total de HAP es significativamente superior en el interior del hogar (ver Tabla 1).

A nivel cuantitativo, la muestra exterior al área de combustión es la que presenta una concentración menor del total de HAP, lo que parece indicar que se trata del nivel de fondo, o blanco, del yacimiento. En el interior y la base del área de combustión, las concentraciones son significativamente mayores, a la vez que el contenido máximo se observa en la superficie. Debe notarse, no obstante, que la muestra de la superficie (FOG1S) se encuentra muy enriquecida en componentes volátiles con respecto a las del interior del área de combustión e incluso con respecto a la muestra exterior (ver porcentajes en la Tabla 1). De hecho, FOG1S correspondía a una capa delgada de sedimento que presentaba coloración y textura distintas de las del resto de sedimento excavado, y que precedía inmediatamente al relleno de la cubeta del área de combustión.

El enriquecimiento en componentes volátiles podría haberse producido por adsorción de éstos al cubrir con tierra el área de combustión humeante. Los HAP de hasta 4 anillos aromáticos se encuentran, en contacto con el aire a temperatura ambiente, preferentemente en la fase gas, por lo que en su mayoría escapan fácilmente a la acumulación de cenizas, forman parte del humo y se dispersan en el aire, a menos que encuentren superficies sólidas donde condensar. En la combustión de madera, estos componentes volátiles o semivolátiles constituyen cuantitativamente la mayor parte del total de los HAP producidos (Ramdahl, 1985), de ahí que no es de extrañar que FOG1S presente las concentraciones más elevadas del área de combustión.

\section{El caso del reteno}

El reteno (1-metil-7-isopropilfenantreno) es un HAP alquil-substituido que resulta de la deshidrogenación del ácido abiético, un diterpenoide muy abundante en resinas de árboles, principalmente de coníferas en climas templados. El proceso de deshidrogenación puede tener lugar por diagénesis natural en la acumulación de ácido abiético en el suelo (Simoneit y Mazurek, 1982), pero las proporciones mayores de reteno se producen durante la combustión de biomasa de coníferas en fuegos forestales o domésticos, 


\begin{tabular}{|c|c|c|c|c|c|c|}
\hline \multicolumn{7}{|c|}{ HOGAR YACIMIENTO MEDIONA I. CONCENTRACIÓN H.A.P. (pg/g) } \\
\hline & & SET1 & FOG1S & FOG2E & FOG3W & FOG4B \\
\hline 1. & DBT & 14 & 425 & 26 & 31 & 20 \\
\hline 2. & $\mathrm{Ph}$ & 93 & 1132 & 281 & 372 & 120 \\
\hline 3. & A & 4 & 66 & 64 & 18 & 3 \\
\hline 4. & C1-DBT & 176 & 3202 & 252 & 315 & 525 \\
\hline 5. & $\mathrm{C} 1-\mathrm{Ph}$ & 371 & 2983 & 326 & 683 & 675 \\
\hline 6. & $\mathrm{C} 2-\mathrm{Ph}$ & 775 & 3532 & 528 & 1262 & 958 \\
\hline 7. & Fla & 81 & 1129 & 287 & 250 & 219 \\
\hline 8. & AcPhen & 9 & 20 & 16 & 87 & 6 \\
\hline 9. & Py & 122 & 1130 & 321 & 631 & 270 \\
\hline 10. & $\mathrm{C} 1-\mathrm{F} / \mathrm{P}$ & 38 & 220 & 28 & 90 & 43 \\
\hline 11. & $\mathrm{BF} 1$ & 7 & 23 & 2 & 5 & 6 \\
\hline 12. & $\mathrm{Re}$ & 16 & 239 & 65 & 151 & 36 \\
\hline 13. & BNT & 35 & 85 & 6 & 13 & 14 \\
\hline 14. & BghiFla & 11 & 47 & 29 & 96 & 10 \\
\hline 15. & $\mathrm{BcPh}$ & 2 & 11 & 6 & 24 & 2 \\
\hline 16. & CPPy & 2 & 2 & 1 & 3 & 1 \\
\hline 17. & $\mathrm{BaA}$ & 8 & 30 & 16 & 63 & 5 \\
\hline 18. & Chry+Tr & 40 & 134 & 85 & 383 & 23 \\
\hline 19. & BFla & 22 & 90 & 97 & 282 & 29 \\
\hline 20. & $\mathrm{BePy}$ & 16 & 55 & 69 & 214 & 17 \\
\hline 21. & $\mathrm{BaPy}$ & 4 & 9 & 12 & 30 & 2 \\
\hline 22. & Per & 2 & 12 & 3 & 8 & 0 \\
\hline 23. & DBA & 38 & 57 & 58 & 136 & 65 \\
\hline 24. & IChry & 12 & 38 & 55 & 120 & 19 \\
\hline 25. & IPy & 26 & 48 & 67 & 153 & 33 \\
\hline 26. & BPer & 31 & 48 & 84 & 192 & 38 \\
\hline 27. & DBPy & 52 & 87 & 86 & 93 & 54 \\
\hline \multirow[t]{2}{*}{28.} & Cor & 78 & 71 & 94 & 201 & 147 \\
\hline & TOTAL & 2082 & 14926 & 2962 & 5907 & 3340 \\
\hline
\end{tabular}

HOGAR YACIMIENTO MEDIONA I. SERIE FENANTRENO, RELACIÓN Ph/Ph+ (C1-Ph) + (C2-Ph)
0.07
0.15
0.25
0.16
0.07

HOGAR YACIMIENTO MEDIONA I. COMPONENTES PRINCIPALES (\%)

$\%$ metilados

$\%$ pirolíticos

$\%$ volátiles

$\% \operatorname{Re}$

65
10
82
0.8

67

2.9

94

1.6

38
15
74
2.2

40

22

66

2.6
66

86

1.1

Tabla 1. Concentración de H.A.P. en las muestras del área de combustión del yacimiento de Mediona I: (1)DBT (dibenzotiofeno), (2)Ph (fenantreno), (3)A (antraceno), (4)C1-DBT (metil-dibenzotiofenos), (5)C1-Ph (metil-fenantrenos), (6)C2-Ph (dimetil-fenantrenos), (7)Fla (fluorantenos), (8)AcPhen (acefenantrileno), (9)Py (pireno), (10)C1F/P (metil-fluorantenos+pirenos), (11)BF1 (benzofluorenos), (12)Re (reteno), (13)BNT (benzonaftotiofenos), (14)BghiFla (benzo $[g h i]$ fluoranteno), (15)BcPh (benzo $[c]$ fenantreno), (16)CPPy (ciclopenta $[c d]$ pireno), (17)BaA (benzo $[a]$ antraceno), (18)Chry+Tr (criseno+trifenileno), (19)BFla (benzofluorantenos), (20)BePy (benzo $[e]$ pireno), (21)BaPy (benzo[ $a]$ pireno), (22)Per (perileno), (23)DBA (dibenzoantraceno), (24)IChry (indeno[7,1,2,3cdef]criseno), (25)IPy (indeno[1,2,3-cd]pireno), (26)BPer (benzo[ghi $]$ perileno), (27)DBPy (dibenzopirenos), (28)Cor (coroneno). 
por lo que se ha propuesto como un buen indicador ambiental de este tipo de combustión (Ramdahl, 1983).

El reteno aparece en todas las muestras del yacimiento (Tabla 1). La concentración mínima corresponde al exterior del hogar, por lo que, como en el caso de los demás HAP, puede considerarse que se trata del nivel de fondo diagenético. La máxima concentración corresponde a la superficie del hogar, por encima del contenido en el interior, de forma parecida a lo que sucedía con el total de HAP. Ello se explica por el carácter semivolátil del reteno, $\mathrm{y}$ indica un origen común de este componente con los demás HAP ligeros.

Por lo que se refiere al contenido relativo, los mayores porcentajes de reteno se observan en el interior del área de combustión. La formación pirolítica de reteno se ve favorecida a bajas temperaturas y con una mala aireación, pudiendo llegar a ser, en estas condiciones, el componente mayoritario (Ramdahl, 1985). El estudio micromorfológico del suelo de una muestra del área de combustión de Mediona I (Taulé, 1992) ha demostrado que éste funcionó en un ambiente reductor, con una temperatura entre $600-800^{\circ} \mathrm{C}$, con lo que cabía esperar niveles moderados de reteno como los que se han observado.

La distribución del reteno confirma, pues, la utilización del área de combustión como tal, e indica que los antiguos pobladores utilizaron madera de conífera como combustible. De hecho, el estudio antracológico del yacimiento (Piqué, 1992) demuestra la presencia de pino (Pinus halepensis, Pinus silvestris y Pinus sp.) en la zona, contemporánea a la utilización del poblamiento.

\section{CONCLUSIONES}

Las composiciones cualitativas y cuantitativas de HAP en las muestras de Mediona I muestran que, a pesar de existir un nivel de fondo de estos compuestos en el yacimiento, en el interior del área de combustión aparece superpuesta una contribución pirogénica claramente diferenciable, que confirma su utilización para la combustión de materia orgánica, y en concreto de madera.

La identificación de reteno en proporciones significativamente altas permite concretar que se utilizó pino como una (aunque quizás no la única) fuente de combustible. Además, la distribución de los HAP en el plano vertical parece confirmar que el hogar fue apagado y abandonado cubriéndolo con tierra.

$\mathrm{El}$ análisis de HAP en muestras arqueológicas de aspecto termoalterado puede ser de gran utilidad para identificar y/o confirmar procesos de combustión cuando la observación macroscópica no ofrece suficiente información. El presente estudio revela inequívocamente la existencia de un área de combustión y complementa los datos de los otros análisis (antracología, micromorfología de suelos, etc.) referidos al funcionamiento de áreas de combustión prehistóricas.

\section{AGRADECIMIENTOS}

Los trabajos de investigación han sido subvencionados por el Departamento de Cultura de la Generalitat de Catalunya, el landesdenkmalamnt de Baden-Wüttemberg, el Instituto Arqueológico Alemán y la empresa Würth.

\section{BIBLIOGRAFÍA}

Estévez, J. y Pique, R. (1990): «Mediona I: un asentamiento del paleolítico medio en Catalunya». Xàbiga, 6: 126-143.

EstéVEZ, J. y Weniger, G. (1991): «El jaciment paleolític de Mediona I». Tribuna d'Arqueologia, 1989-1990: 717.

Estévez, J.; Pique, R.; Vila, A.; Bonet, A.; Clemente, I.; TAUlé, M. y Weniger, G. (1993): «El poblamiento prehistórico en la cuenca del Mediona (Alt Penedès. Barcelona)". Trabalhos de Antropologia e Etnologia, $33(3-4): 1-132$.

Li, C.K. y KAMENS, R.M. (1993): «The use of polycyclic aromatic hydrocarbons as source signatures in receptor modeling». Atmospheric Environment, 27A: 523-532.

MARCH, R.J.; BALDESSARI, A. y GRoss, E. (1989): «Determinación de compuestos orgánicos en estructuras de combustión arqueológicas». Actes du colloque de Nemours 1987. Memoires du Musée de Préhistoire d'Ille de France, 2: 47-58.

MARCH, R.J.; BALDESSARI, A. y FerRerI, J. (1991): «Étude des structures de combustion archéologiques d'Argentine». Bulletin de la Société Préhistorique Française, 86, 1989. Études et Travaux, 10-12.

Miller, J.A. y FISK, G.A. (1987): «Combustion Chemistry». $C \& E N$, August: 22-46.

PIQUÉ, R. (1990): «Untersuchungen der holzkohlen von Mediona I». Madrider Mitteilungen, 31: 10-12.

RAMDAHL. T. (1983): «Retene -a molecular marker of wood combustion in ambient air». Nature, 306: 580582. 
- (1985): «PAH emissions from combustion of biomass», A. Bjorseth y T. Ramdahl (ed.): Handbook of polycyclic aromatic Hydrocarbons, 2. M. Dekker Inc.: 61-85.

ROTTLÄNDER, R.C.A. (1976): «Variation in the chemical composition of bone as an indicator of climatic change». Journal of Archaeological Science, 3: 1-6.

- (1986): «Die resultate der modernen fettanalytik und ihre anwendung auf die prähistorische forschung». Archaeophysika, 12. Naturwissen-schaftliche. Beiträge zur archäologie, 2.

- (1990): «Investigations into a vessel of the Cyclades». Fresednius Journal Analytical Chemistry, 338: 138-139.

Simó, R.; Grimalt, J.O.; Colom-Altés, M. y Albaigés, J. (1991)a: «The lipid composition of the Western Mediterrane an aerosol». Fresedenius Journal Analytical Chemistry, 339: 757-764.

Simó, R.; Colom-Altés, M.; Grimalt, J.O. y Albaigés, J. (1991)b: «Background levels of atmospheric hydrocarbons, sulfate and nitrate over the Western Mediterranean». Atmospheric Environment, 25A: 1463-1471.
SiMONEIT, B.R.T. y MAZUREK, M.A. (1982): «Organic matter of the troposphere -II. Natural background of biogenic lipid matter in aerosols over the rural Western United States». Atmospheric Environment, 16: 2139 2159.

TAULÉ, M.A. (1993): «La micromorfología de suelos como técnica para el análisis de rasgos edáficos de origen antrópico". Procesos Postdeposicionales. Arqueología Espacial, 16-17: 353-362. Teruel.

VENKATESAN, M I. y DAHL, J. (1989): «Organic geochemical evidence for global fires at the Cretaceous/Tertiary boundary». Nature, 338: 57-60.

WúNSCH. G. (1991): «L'estudi de les associacions d'elements de combustió - AEC- en el marc de l'anàlisi de les interrelacions espaials dels elements arqueològicsANITES-: Una reflexió teòrico-metodològica». Tesi doctoral. Ed. microficha. Universitat Autónoma de Barcelona. 